\title{
REVIEW
}

\section{Pain in Intensive Care: A Narrative Review}

\author{
Vincenzo Pota (D) - Francesco Coppolino · Alfonso Barbarisi • \\ Maria Beatrice Passavanti · Caterina Aurilio · Pasquale Sansone • \\ Maria Caterina Pace
}

Received: November 12, 2021 / Accepted: February 9, 2022 / Published online: February 27, 2022

(C) The Author(s) 2022

\section{ABSTRACT}

All critically ill adult patients in intensive care units (ICU) typically experience pain. Critically ill adults suffer pain of different intensities. It depends on individual characteristics, specific procedural interventions, and underlying diseases. Inadequate management of acute pain is a risk factor for the emergence of chronic pain, where the incidence is up to $33 \%$ into the ICU survivor population. For the management of pain, agitation, and delirium, several coexisting clinical practice guidelines have been published. The first problem is that the patient recovered in intensive care unit should not be able to communicate its pain state. Opioids are the analgesic drugs of choice in critically ill patients with non-neuropathic pain. All intravenous opioids have the same effects, respecting the equianalgesic table. Observational research has shown that opioids are the main analgesic treatment in over $80 \%$ of mechanically ventilated patients. It is interesting that opioid

V. Pota $(\bowtie) \cdot$ F. Coppolino $\cdot$ M. B. Passavanti

C. Aurilio - P. Sansone - M. C. Pace

Department of Women, Child, General and

Specialistic Surgery, University of Campania

"L. Vanvitelli", Naples, Italy

e-mail: vincenzo.pota@unicampania.it

A. Barbarisi

Department of Translational Medical Science,

Telematic University Pegaso, Naples, Italy consumption in an ICU and the memory of painful experience are linked to the development of post-traumatic stress disorder after ICU discharge. In order to reduce the side effects and maintain analgesia, it is useful to associate adjuvant medications with opioids. An opportunity to improve patients' experience in an ICU is to manage pain through multimodal approaches.

Keywords: Intensive care; Acute pain; Procedural pain; Assessment; Delirium

\section{Key Summary Points}

All critically ill adult patients in medical, surgical, and trauma intensive care units (ICU) typically experience pain.

For the management of pain, agitation, and delirium, several coexisting clinical practice guidelines have been published.

Multimodal approaches to pain management present an opportunity to improve patients' experiences of critical illness as well as patient outcomes. 


\section{INTRODUCTION}

All critically ill adult patients in medical, surgical, and trauma intensive care units (ICU) typically experience pain, both at rest and under routine ICU care, and have the right to receive adequate pain management where required [1]. The origin of pain can be surgery, trauma, burns, or cancer [2-9]. Pain is a frequent event in intensive care unit (ICU) patients, with an incidence of up to $50 \%$ in medical as well as surgical patients [10]. Pain is associated with an acute stress response including changes in neurovegetative system activity [11], neuroendocrine secretion [12, 13], and psychological distress often manifested as agitation [14].

\section{METHODS}

We conduct a narrative review on pain in intensive care because it is most useful for obtaining a broad perspective on that topic and because a lot of data come from routine (uncontrolled) clinical practice. We used the PubMed database and analyzed all relevant papers (narrative review, systematic review, and meta-analysis randomized controlled trial, prospective trial, and case report) dealing with the keywords: intensive care, acute pain, procedural pain, pain assessment in ICU, and pain management in ICU. The timeline was from 1990 to 2020 . We included 55 articles and the criteria for inclusion was that they were metaanalysis, narrative or systematic review or RCT, prospective, retrospective or case-control study, we excluded case report and case series.

This article is based on previously conducted studies and does not contain any new studies with human participants or animals performed by any of the authors.

\section{RESULTS}

\section{Assessment}

The International Association for the Study of Pain defines pain as an "unpleasant sensory and emotional experience associated with actual or potential tissue damage, or described in terms of such damage" [15]. The first problem is that the patient recovered in intensive should not be able to communicate its pain state, so it is fundamental to distinguish between a patient able to communicate and one not able to communicate. Vital signs (elevated blood pressure, elevated heart rate, modification in respiratory rate) alone have been considered poor indicators of pain. Some recent techniques have been proposed for pain evaluation and scoring, like pupillometry, changes in Bispectral Index or processed EEG signals, but further studies are necessary to validate them. Modern analgesia strategies propose a management based on adaptive analgesia or dynamic analgesia. It is important to focus on titrate pain therapy on the patients' changing clinical situations. In the ICU, there is the problem either of inappropriate pain control then over treatment of painfull condition. Uncontrolled pain may lead to prolonged mechanical ventilation, increased ICU length of stay, pulmonary complications, patient-ventilator asynchrony, post-traumatic disorder. The over-treatment of pain may lead to prolonged mechanical ventilation, prolonged cognitive impairment, delirium, respiratory depression, hemodynamic impairment and so on. Patients and professional caregivers must become more knowledgeable about the necessity of simultaneously managing pain and stabilizing underlying medical conditions. Both pain agitation and delirium (PAD) guidelines published form The American College of Critical Care Medicine (ACCM) in 2013 and Japanese Pain Agitation and Delirium (J-PAD) guidelines in 2013 recommend (grade $+1 \mathrm{~B}$ ) routine monitoring of pain (every $4 \mathrm{~h}$ ) in adult patients in the ICU. $[16,17]$ The patient's selfreport of pain is considered the "gold standard," and clinicians should always attempt to have a first rate of his or her pain of the patient. Chanques and colleagues compared five selfreport intensity scales in over 100 ICU patients and demonstrated that a $0-10$ visually enlarged horizontal numeric rating scale (NRS) was the most valid and feasible of five pain intensity rating scales tested (Fig. 1) [18]. In case the patient is unable to communicate, the 


\section{NRS PAIN SCALE}

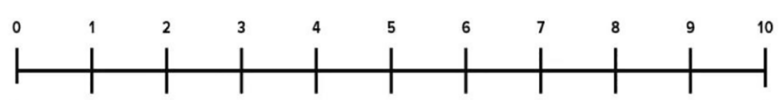

Fig. 1 Numeric Rating Scale (NRS)

Federacion Panamericana e Iberica de Sociedades de Medicina Critica y Terapia Intensiva (FEPIMCTI) guidelines recommend using a behavioral pain scale (BPS), while the PAD and J-PAD have yet recommended the use of BPS or the Critical-Care Pain Observation Tool (CPOT) $[19,20]$. The BPS and the CPOT are the most effective and dependable behavioral pain scales for the evaluation of pain in adult ICU patients unable to self-report. These scales are also not valid in case of brain injury, in patients with motor function disease, and when their behaviors are not observable.

\section{Management of Pain, Agitation, and Delirium}

It is difficult to separate pain management from sedation in the ICU context. The FEPIMCTI and $\mathrm{J}$-PAD guidelines recommend (grade $1 \mathrm{~B}$ ) prompt identification and treatment of the possible underlying causes of agitation, such as pain, delirium, hypoxemia, hypotension, or withdrawal from alcohol and other drugs. The Richmond Agitation-Sedation Scale (RASS) and Sedation-Agitation Scale are the most valid and reliable sedation assessment tools for measuring quality and depth of sedation in adult ICU patients, basing on the several guidelines just now published $[21,22]$. All the three previous guidelines recommend "analgesia-first sedation" in such patients. The use of propofol, dexmedetomidine, or midazolam is recommended. A summary of the principal recommendations of evidence-based guidelines includes:

- Vital signs alone should not be used for pain assessment;

- Analgesia should be administered prior to painful procedures;
- Sedation levels should be titrated to lightlevel rather than deep sedation;

- Use of "care bundle" for managing pain, agitation, and delirium: "analgesia first" sedation strategy; promoting sleep and establishing day-night routine; and interdisciplinary team approach.

Opioids are the analgesic drug of choice in critically ill patients with non-neuropathic pain. All intravenous opioids have the same effects, respecting the equianalgesic table [23-27]. Intravenous opioids are recommended as the first-line treatment for pain management in ICU patients. Both PAD and FEPIMCTI guidelines recommended remifentanil. The choice of the better opioid and its dose for each specifically patient is related to many factors, as the pharmacokinetic and pharmacodynamic properties of the drug [28]. It is important to avoid the use of meperidine in ICU patients. The motivation is the metabolism of meperidine and the kidney diseases usually present in the ICU, the potential interaction with other drugs like monoamine oxidase inhibitors and selective serotonin re-uptake inhibitors, and finally because of the neurologic toxicity [28]. Except for meperidine, the evidence in favor of the use of one opioid instead of another one is very poor. The opioid use has not to be indiscriminate, otherwise the emergency of side effects can have serious and detrimental effects in ICU patients. The more frequent side effects include respiratory depression, nausea, vomiting, constipation, tolerance, and physical dependence. The appearance, as a side effect, of bowel dysfunction [29], and ileus can determinate a prolonged hospital stay and can increase morbidity. So it is in contrast with actual protocols that focus on early recovery after surgery and the prevention of ileus in the perioperative period [30]. Fentanyl is a shot acting drug when administered as single dose 
because of redistribution. It is, therefore, to consider that its long elimination half-life can determinate its accumulation when given in high doses for long periods. It has to be considered that fentanyl is safe in patient with kidney failure because it is metabolized from the liver with the production inactive metabolities. For these reasons, fentanyl has been recommended as the analgesic of choice in critically ill patients, especially in those case with hemodynamic impairment [31]. Remifentanil and alfentanil also present favorable kinetics for use in patients with organ dysfunction. Several study have showed as the association of alfentanil and propofol led to reduce the extubation time and the time to discharge form ICU, when compared with combination of morphine and midazolam [32]. Remifentanil has a rapid clearance that is independent of renal function [33]. A meta-analysis has demonstrated that remifentanil compared with either another opioid or hypnotic agent did not present superiority in terms of mortality, length of mechanical ventilation, length of ICU stay, and risk of development of agitation [34]. It is important to underline that in patients able to tolerate enterally administered medications, the enteral administration of opioids should be chosen [31].

In order to guarantee a better analgesia and reduce the adverse side effects, it's useful the association of opioids with adjuvant medications. Non-opioid analgesics can improve the overall efficacy of analgesia and/or reduce opioid requirements in ICU patients [35]. A systematic review and meta-analysis published in 2020, which examined 34 trials [36], represents the most comprehensive study on the use of adjuvant analgesic medications in ICU patients: dexmetedomidine, nonsteroidal anti-inflammatory drugs (NSAIDs) (including diclofenac, indomethacin, and ketoprofen), ketamine, nefopam, gabapentin carbamazepine, clonidine, magnesium sulfate, pregabalin. It has been described that the association of opioids with adjuvant is able to reduced pain in ICU patients. The main limitation in using nonopioids is due to their potential organ toxicity (principally renal and hepatic). Furthermore, several trials have demonstrated that intravenous acetaminophen is safe and effective when used in combination with opioids for postoperative pain relief both in major and cardiac surgery [26, 37-41]. In particular, the association to opioids with $1 \mathrm{gr}$ of intravenous paracetamol every $6 \mathrm{~h}$ improves analgesia and reduce the extubation times in elective cardiac surgical. Based on the present literature, we suggest that non-opioid analgesics should be used in order to reduce opioid consumption, eliminate the need of rescue dose of IV opioids, and reduce side effects related to opioid medication. Although analgesia provided from NSAIDs is equivalent to that of acetaminophen, NSIADs should be used with caution in patients with renal injury, congestive heart failure, and those with a risk of bleeding. Dexmedetomidine is an alpha ${ }_{2}$-adrenergic agonist $(\mathrm{C} 13 \mathrm{H} 16 \mathrm{HCl})$, comparable for its structure to clonidine but it is more selective and has got a greater affinity towards alpha ${ }_{2}$-receptors over alpha ${ }_{1}$-receptors [42]. It is the dextrorotatory $S$-enantiomer of medetomidine chemically described as (+)-4(2,3-dimethyle phenyl) ethyl-1H-imidazole monohydrochloride. In ICU dexmedetomidine is able to maintain a patient light to moderate sedation also in patients receiving prolonged mechanical ventilation. The comparison of dexmedetomidine and midazolam showed that dexmedetomidine is able to reduce the lenght of mechanical ventilation. and a better improvement patients' ability to communicate pain [43]. Dexmedetomidine has an opioidsparing effect, so it can reduce opioid requirements in critically ill patients [44-46]. Adequate postoperative and post-trauma pain management is also fundamental for the achievement of effective rehabilitation. When used correctly, and in association with other treatment modalities, the regional analgesia may reduce or eliminate the physiological stress response to surgery and trauma and may reduce the opioid consumption necessary to achieve adequate pain control and the development of potentially dangerous side effects [47]. 


\section{Specific Painful Conditions}

Pain in Guillain-Barré syndrome (GBS) is common in intensive care, but it is often not recognized and not well managed. In recent years, several pharmacological therapies have been investigated in order to treat GBS-associated pain. A recent review does not provide sufficient evidence to support the use of any pharmacological treatments in people with pain in GBS; even in pain management in GBS is fundamental. In a recent paper Gabapentin and carbamazepine were able to determinate a pain reduction in GBS but the evidence was limited and its quality very low [48]. Other specific drugs, like intravenous methylprednisolone in combination with intravenous immunoglobulins (IVIG), may accelerate the recovery of the patient but does not have any effect on neuropathic pain from [49].

Intensive care unit (ICU) patients undergo numerous diagnostic and therapeutic procedures each day [50]. A large prospective, crosssectional, multicenter, study on pain intensity related to 12 procedures was conducted in 192 ICUs in 28 countries. The most painful procedures described from authors were chest tube removal, wound drain removal, and arterial line insertion. By multivariate analysis, risk factors independently associated with a more intense procedural pain were: the specific procedure, opioid administration, preprocedural pain, intensity of the worst pain on the same day, before the procedure, and procedure not performed by a nurse. It is very important that adequate local and/or parenteral anesthesia should be provided during any procedure, which could evocate pain $[51,52]$. One study compared the efficacy of remifentanil $0.5 \mathrm{mg} / \mathrm{kg}$ versus placebo for the treatment of pain related to chest tube removal. It demonstrated that patients receiving remifentanil showed significantly less pain than patients receiving a placebo [52]. In another study [53], patients treated with intravenous fentanyl $(2 \mu \mathrm{g} / \mathrm{kg})$ or sufentanil $0.2(\mu \mathrm{g} / \mathrm{kg})$ suffered from significantly lower pain scores than patients treated with $2 \mathrm{ml}$ of normal saline. Finally, a recent randomized controlled study suggests that the combination subcutaneous administration of
$1 \%$ lidocaine and multimodal analgesia is most efficacious in terms of analgesia [54].

\section{CONCLUSIONS}

Firstly, this is a narrative review, so it has some limitations: the nature of the method is too subjective, the possibility of misleading in drawing conclusions (that are normally due to selection bias), subjective weighing of the studies chosen for the review, unspecified inclusion criteria, and failure to consider the relationships between study characteristics and study results. All critically ill adult patients experience pain. Several clinical practice guidelines on pain management and treatment intensive care setting have been published. Opioids are the analgesic of choice in critically ill patients with non-neuropathic pain. The use of adjuvant medications, in combination with opioids, may provide an improvement in effective analgesia and minimize unwanted side effects. It certain that the multimodal approaches to pain management is an opportunity to improve patients' pain experience of ICU stay as well as patient short- and long-term outcomes.

\section{ACKNOWLEDGEMENTS}

Funding. No funding or sponsorship was received for this study or publication of this article.

Authorship. All named authors meet the International Committee of Medical Journal Editors (ICMJE) criteria for authorship for this article, take responsibility for the integrity of the work as a whole, and have given their approval for this version to be published.

Author Contributions. Conceptualization: V.P., C.A, M.C.P; Writing-review and editing: C.P, M.B.P. Supervision: A.F, P.S.

Disclosures. Vincenzo Pota, Francesco Coppolino, Alfonso Barbarisi, Maria Beatrice Passavanti, Caterina Aurilio, Pasquale Sansone and 
Maria Caterina Pace declare that they have no conflicts of interest to disclose.

Compliance with Ethics Guidelines. This article is based on previously conducted studies and does not contain any new studies with human participants or animals performed by any of the authors.

Open Access. This article is licensed under a Creative Commons Attribution-NonCommercial 4.0 International License, which permits any non-commercial use, sharing, adaptation, distribution and reproduction in any medium or format, as long as you give appropriate credit to the original author(s) and the source, provide a link to the Creative Commons licence, and indicate if changes were made. The images or other third party material in this article are included in the article's Creative Commons licence, unless indicated otherwise in a credit line to the material. If material is not included in the article's Creative Commons licence and your intended use is not permitted by statutory regulation or exceeds the permitted use, you will need to obtain permission directly from the copyright holder. To view a copy of this licence, visit http://creativecommons.org/licenses/by$\mathrm{nc} / 4.0 /$.

\section{REFERENCES}

1. Tsuruta R, Fujita M. Comparison of clinical practice guidelines for the management of pain, agitation, and delirium in critically ill adult patients. Acute Med Surg. 2018;5(3):207-12. https://doi.org/10. 1002/ams2.337 (Published 10 Apr 2018).

2. Stanik-Hutt JA, Soeken KL, Belcher AE, Fontaine DK, Gift AG. Pain experiences of traumatically injured patients in a critical care setting. Am J Crit Care. 2001;10(4):252-9 (PMID: 11432213.Stotts).

3. Stotts NA, Puntillo K, Stanik-Hutt J, Thompson CL, White C, Wild LR. Does age make a difference in procedural pain perceptions and responses in hospitalized adults? Acute Pain. 2007;9(3):125-34. https://doi.org/10.1016/j.acpain.2007.07.001.

4. Stotts NA, Puntillo K, Bonham Morris A, et al. Wound care pain in hospitalized adult patients.
Heart Lung. 2004;33(5):321-32. https://doi.org/10. 1016/j.hrtlng.2004.04.001 (PMID: 15454911).

5. Arroyo-Novoa CM, Figueroa-Ramos MI, Puntillo $\mathrm{KA}$, et al. Pain related to tracheal suctioning in awake acutely and critically ill adults: a descriptive study. Intensive Crit Care Nurs. 2008;24(1):20-7. https://doi.org/10.1016/j.iccn.2007.05.002 (Epub 2007 Aug 6. PMID: 17689249).

6. Puntillo K, Ley SJ. Appropriately timed analgesics control pain due to chest tube removal. Am J Crit Care. 2004;13(4):292-301 (discussion 302; quiz 303-4. PMID: 15293581).

7. Puntillo KA, White C, Morris AB, et al. Patients' perceptions and responses to procedural pain: results from Thunder Project II. Am J Crit Care. 2001;10(4):238-51 (PMID: 11432212).

8. Puntillo KA. Dimensions of procedural pain and its analgesic management in critically ill surgical patients. Am J Crit Care. 1994;3:116-22.

9. Puntillo KA. Effects of interpleural bupivacaine on pleural chest tube removal pain: a randomized controlled trial. Am J Crit Care. 1996;5:102-8.

10. Chanques G, Pohlman A, Kress JP, et al. Psychometric comparison of three behavioural scales for the assessment of pain in critically ill patients unable to self-report. Crit Care. 2014;18(5):R160. https://doi.org/10.1186/cc14000 25063269; PMCID: PMC4220092).

(PMID:

11. de Jong A, Molinari N, de Lattre S, et al. Decreasing severe pain and serious adverse events while moving intensive care unit patients: a prospective interventional study (the NURSE-DO project). Crit Care. 2013;17(2):R74. https://doi.org/10.1186/ cc12683 (PMID: 23597243; PMCID: PMC3672726).

12. Page GG, Blakely WP, Ben-Eliyahu S. Evidence that postoperative pain is a mediator of the tumor-promoting effects of surgery in rats. Pain. 2001;90(1-2): 191-9. https://doi.org/10.1016/s03043959(00)00403-6 (PMID: 11166986).

13. Greisen J, Juhl CB, Grøfte T, Vilstrup H, Jensen TS, Schmitz O. Acute pain induces insulin resistance in humans. Anesthesiology. 2001;95(3):578-84. https://doi.org/10.1097/00000542-20010900000007 (PMID: 11575527).

14. Jaber S, Chanques G, Altairac C, et al. A prospective study of agitation in a medical-surgical ICU: incidence, risk factors, and outcomes. Chest. 2005;128(4):2749-57. https://doi.org/10.1378/ chest.128.4.2749 (PMID: 16236951). 
15. Merskey H, Albe Fessard D, Bonica JJ, Carmon A, Dubner R, Kerr FWL, Lindblom U, Mumford JM, Nathan PW, Noordenbos W, Pagni CA, Renaer MJ, Sternbach RA, Sunderland S. Pain terms: a list with definitions and notes on usage. Recommended by the IASP subcommittee on taxonomy. Pain. 1979;6: 249-52.

16. Barr J, Fraser GL, Puntillo K, et al. Clinical practice guidelines for the management of pain, agitation, and delirium in adult patients in the intensive care unit. Crit Care Med. 2013;41(1):263-306. https:// doi.org/10.1097/CCM.0b013e3182783b72 (PMID: 23269131).

17. Committee for the development of Japanese guidelines for the management of pain, agitation, and delirium in intensive care unit, Japanese Society of Intensive Care Medicine. Japanese guidelines for the management of Pain, Agitation, and Delirium in intensive care unit (J-PAD). J Jpn Soc. Intensive Care Med. 2014;21:539-79.

18. Chanques G, Viel E, Constantin JM, et al. The measurement of pain in intensive care unit: comparison of 5 self-report intensity scales. Pain. 2010;151(3):711-21. https://doi.org/10.1016/j. pain.2010.08.039 (Epub 2010 Sep 16. PMID: 20843604).

19. Payen JF, Bru O, Bosson JL, et al. Assessing pain in critically ill sedated patients by using a behavioral pain scale. Crit Care Med. 2001;29(12):2258-63. https://doi.org/10.1097/00003246-20011200000004 (PMID: 11801819).

20. Gélinas C, Johnston C. Pain assessment in the critically ill ventilated adult: validation of the Critical-Care Pain Observation Tool and physiologic indicators. Clin J Pain. 2007;23(6):497-505. https://doi.org/10.1097/AJP.0b013e31806a23fb (PMID: 17575489).

21. Sessler CN, et al. The Richmond Agitation-Sedation Scale: validity and reliability in adult intensive care unit patients. Am J Respir Crit Care Med. 2002;166: 1338-44.

22. Riker RR, Picard JT, Fraser GL. Prospective evaluation of the Sedation-Agitation Scale for adult critically ill patients. Crit Care Med. 1999;27(7):1325-9. https://doi.org/10.1097/00003246-19990700000022 (PMID: 10446827).

23. Machata AM, Illievich UM, Gustorff B, Gonano C, Fässler K, Spiss CK. Remifentanil for tracheal tube tolerance: a case control study. Anaesthesia. 2007;62(8):796-801. https://doi.org/10.1111/j. 1365-2044.2007.05100.x (PMID: 17635427).

24. Krishnan K, Elliot SC, Berridge JC, Mallick A. Remifentanil patient-controlled analgesia following cardiac surgery. Acta Anaesthesiol Scand. 2005;49(6):876-9. https://doi.org/10.1111/j.13996576.2005.00729.x (PMID: 15954975).

25. Dahaba AA, Grabner T, Rehak PH, List WF, Metzler H. Remifentanil versus morphine analgesia and sedation for mechanically ventilated critically ill patients: a randomized double blind study. Anesthesiology. 2004;101(3):640-6. https://doi.org/10. 1097/00000542-200409000-00012 15329588).

26. Memis D, Inal MT, Kavalci G, Sezer A, Sut N. Intravenous paracetamol reduced the use of opioids, extubation time, and opioid-related adverse effects after major surgery in intensive care unit. J Crit Care. 2010;25(3):458-62. https://doi.org/10. 1016/j.jcrc.2009.12.012 (Epub 2010 Mar 1 PMID: 20189753).

27. DAS-Taskforce 2015, Baron R, Binder A, et al. Evidence and consensus based guideline for the management of delirium, analgesia, and sedation in intensive care medicine. Revision 2015 (DASGuideline 2015)—short version. Ger Med Sci. 2015;13:Doc19. https://doi.org/10.3205/000223 (PMID: 26609286; PMCID: PMC4645746).

28. Erstad BL, Puntillo K, Gilbert HC, et al. Pain management principles in the critically ill. Chest. 2009;135(4):1075-86. https://doi.org/10.1378/ chest.08-2264.

29. Polaner DM, Taenzer AH, Walker BJ, et al. Pediatric Regional Anesthesia Network (PRAN): a multi-institutional study of the use and incidence of complications of pediatric regional anesthesia. Anesth Analg. 2012;115(6):1353-64. https://doi.org/10. 1213/ANE.0b013e31825d9f4b (Epub 2012 Jun 13. PMID: 22696610).

30. Kurz A, Sessler DI. Opioid-induced bowel dysfunction: pathophysiology and potential new therapies. Drugs. 2003;63(7):649-71. https://doi.org/10.2165/ 00003495-200363070-00003 (PMID: 12656645).

31. Ehieli E, Yalamuri S, Brudney CS, Pyati S. Analgesia in the surgical intensive care unit. Postgrad Med J. 2017;93(1095):38-45. https://doi.org/10.1136/ postgradmedj-2016-134047 (Epub 2016 Oct 24 PMID: 27777355).

32. Manley NM, Fitzpatrick RW, Long T, Jones PW. A cost analysis of alfentanil+propofol vs morphine+midazolam for the sedation of critically ill patients. Pharmacoeconomics. 1997;12(2 Pt 2): 247-55. https://doi.org/10.2165/00019053199712020-00015 (PMID: 10170449).

33. Cohen J, Royston D. Remifentanil. Curr Opin Crit Care. 2001;7(4):227-31. https://doi.org/10.1097/ 00075198-200108000-00003 (PMID: 11571418). 
34. Tan JA, Ho KM. Use of remifentanil as a sedative agent in critically ill adult patients: a meta-analysis. Anaesthesia. 2009;64(12):1342-52. https://doi.org/ 10.1111/j.1365-2044.2009.06129.x (Epub 2009 Oct 22 PMID: 19849681).

35. Joffe AM, Hallman M, Gélinas C, Herr DL, Puntillo K. Evaluation and treatment of pain in critically ill adults. Semin Respir Crit Care Med. 2013;34(2): 189-200. https://doi.org/10.1055/s-0033-1342973 (Epub 2013 May 28 PMID: 23716310).

36. Jefferies S, Saxena M, Young P. Paracetamol in critical illness: a review. Crit Care Resusc. 2012;14(1):74-80 (PMID: 22404066).

37. Wheeler KE, Grilli R, Centofanti JE, et al. Adjuvant analgesic use in the critically ill: a systematic review and meta-analysis. Crit Care Explor. 2020;2(7): e0157. 0000000000000157.

38. Darce K. Cadence wins FDA nod to sell IV pain treatment. Intravenous acetaminophen will be marketed for hospital patients. San Diego UnionTribune News Nov. 2, 2010.

39. Pettersson PH, Jakobsson J, Owall A. Intravenous acetaminophen reduced the use of opioids compared with oral administration after coronary artery bypass grafting. J Cardiothorac Vasc Anesth. 2005;19(3):306-9. https://doi.org/10.1053/j.jvca. 2005.03.006 (PMID: 16130055).

40. Candiotti KA, Bergese SD, Viscusi ER, Singla SK, Royal MA, Singla NK. Safety of multiple-dose intravenous acetaminophen in adult inpatients. Pain Med. 2010;11(12):1841-8. https://doi.org/10. 1111/j.1526-4637.2010.00991.x

(PMID: 21134123).

41. Bignami E, Castella A, Pota V, et al. Perioperative pain management in cardiac surgery: a systematic review. Minerva Anestesiol. 2018;84(4):488-503. https://doi.org/10.23736/S0375-9393.17.12142-5 (Epub 2017 Oct 12. PMID: 29027773).

42. Wagner DS, Brummett CM. Dexmedetomidine: as safe as safe can be. Semin Anesth Perioper Med Pain. 2006;25:77-83.

43. Jakob SM, Ruokonen E, Grounds RM, Dexmedetomidine for Long-Term Sedation Investigators, et al. Dexmedetomidine vs midazolam or propofol for sedation during prolonged mechanical ventilation: two randomized controlled trials. JAMA. 2012;307(11):1151-60. https://doi.org/10.1001/ jama.2012.304 (PMID: 22436955).

44. Venn RM, Grounds RM. Comparison between dexmedetomidine and propofol for sedation in the intensive care unit: patient and clinician perceptions. $\mathrm{Br}$ J Anaesth. 2001;87(5):684-90. https://doi.org/10.1093/bja/87.5.684 (PMID: 11878517).

45. Riker RR, Shehabi Y, Bokesch PM, et al. Dexmedetomidine vs midazolam for sedation of critically ill patients: a randomized trial. JAMA. 2009;301(5):489-99. https://doi.org/10.1001/jama. 2009.56 (Epub 2009 Feb 2. PMID: 19188334).

46. Herr DL, Sum-Ping ST, England M. ICU sedation after coronary artery bypass graft surgery: dexmedetomidine-based versus propofol-based sedation regimens. J Cardiothorac Vasc Anesth. 2003;17(5):576-84. https://doi.org/10.1016/s10530770(03)00200-3 (PMID: 14579210).

47. De Pinto M, Dagal A, O'Donnell B, Stogicza A, Chiu S, Edwards WT. Regional anesthesia for management of acute pain in the intensive care unit. Int J Crit Illn Inj Sci. 2015;5(3):138-43. https://doi.org/ 10.4103/2229-5151.164917 (PMID: 26557482; PMCID: PMC4613411).

48. Liu J, Wang LN, McNicol ED. Pharmacological treatment for pain in Guillain-Barré syndrome. Cochrane Database Syst Rev. 2015;2015(4): CD009950. https://doi.org/10.1002/14651858. CD009950.pub3 (PMID: 25855461; PMCID: PMC6361619).

49. Wijdicks EF, Klein CJ. Guillain-Barré syndrome. Mayo Clin Proc. 2017;92(3):467-79. https://doi. org/10.1016/j.mayocp.2016.12.002 28259232).

50. Puntillo KA, Max A, Timsit J, et al. Determinants of procedural pain intensity in the intensive care unit. The Europain ${ }^{\circledR}$ study. Am J Respir Crit Care Med. 2014;189(1):39-47. https://doi.org/10.1164/rccm. 201306-1174OC (PMID: 24262016).

51. Puntillo KA, Morris AB, Thompson CL, Stanik-Hutt J, White CA, Wild LR. Pain behaviors observed during six common procedures: results from Thunder Project II. Crit Care Med. 2004;32(2): 421-7. https://doi.org/10.1097/01.CCM. 0000108875.35298.D2 (PMID: 14758158).

52. Casey E, Lane A, Kuriakose D, et al. Bolus remifentanil for chest drain removal in ICU: a randomized double-blind comparison of three modes of analgesia in post-cardiac surgical patients. Intensive Care Med. 2010;36(8):1380-5. https://doi.org/10. 1007/s00134-010-1836-2 (PMID: 20237760).

53. Joshi VS, Chauhan S, Kiran U, Bisoi AK, Kapoor PM. Comparison of analgesic efficacy of fentanyl and sufentanil for chest tube removal after cardiac surgery. Ann Card Anaesth. 2007;10(1):42-5. https:// doi.org/10.4103/0971-9784.37923 17455407). 
54. Pinheiro VF, da Costa JM, Cascudo MM, Pinheiro Êde O, Fernandes MA, de Araujo IB. Analgesic efficacy of lidocaine and multimodal analgesia for chest tube removal: a randomized trial study. Rev
Lat Am Enfermagem. 2015;23(6):1000-6. https:// doi.org/10.1590/0104-1169.0498.2642 (Erratum in: Rev Lat Am Enfermagem. 2016 Jul 11;24: e2792. PMID: 26625989; PMCID: PMC4663998). 